\title{
TRABALHO INFANTO-JUVENIL E FORMAÇÃO HUMANA: LIMITES NA POTÊNCIA ONTOLÓGICA E BANALIZAÇÃO DO SUJEITO DE DIREITOS
}

\author{
CHILD LABOR AND HUMAN DEVELOPMENT: LIMITS ON ONTOLOGICAL POWER AND \\ BANALIZATION OF THE SUBJECT OF RIGHTS
}

Laura Souza Fonseca ${ }^{1}$

Resumo Neste artigo, retomam-se concepções e práticas sobre o trabalho infanto-juvenil, analisadas na tese da autora e em pesquisas em andamento, para problematizar, na relação trabalho e educação, as possibilidades deste ser social criança e adolescente. Em continuidade aos estudos, investiga-se uma política de erradicação do trabalho infanto-juvenil e uma rede de proteção inseridas no escopo da proteção integral. Debruça-se sobre a relação trabalho e formação do infanto-juvenil e dos trabalhadores de políticas sociais que integram as condicionalidades para a bolsa do Programa de Erradicação do Trabalho Infantil (Peti). A escrita está organizada em três seções: a historicidade do trabalho infanto-juvenil no processo de acumulação capitalista, a produção do Grupo de Trabalho 'Trabalho e Educação', da Associação Nacional de Pós-Graduação e Pesquisa em Educação (Anped) sobre o tema e a atualidade da questão. Assim, a exposição vinca o objeto 'trabalho infantojuvenil' como produto e motor da acumulação que, com nuances, permanece funcional ao capital. As sucessivas reestruturações produtivas associadas aos modos de gestão do Estado enfraquecem os movimentos na legislação trabalhista em nível internacional e, no caso brasileiro, os avanços representados pelo Estatuto da Criança e do Adolescente (ECA), o que mantém e aprofunda essa chaga social.

Palavras-chave trabalho infanto-juvenil; ser social; sujeito de direitos; acumulação por 'despossessão'; trabalho e formação humana.
Abstract In this article, child labor concepts and practices are taken up again, as analyzed in the author's thesis and ongoing research, to question, in the relationship between work and education, the possibilities of this child and adolescent social being. Giving continuity to the studies, an investigation is made of a policy of eradicating child labor and of having a safety network included in the scope of full protection. The author focuses on the relationship between work and training of both child and young workers and of those who work on the social policies that are part of the conditionalities for the fellowship under the Program for the Eradication of Child Labor (Peti). The text is organized into three sections: the historicity of child labor in the capitalist accumulation process, the production of the 'Work and Education' Working Group, of the National Association of Graduate Studies and Research in Education (Anped) on the theme, and current status of the issue. Thus, the article emphasizes the 'child labor' object as both the product and engine of the accumulation which, with nuances, remains functional to capital. The successive productive restructuring processes associated with the State's management modes weaken the movements in labor laws on the international level and, in the Brazilian case, the progress represented by the Children and Adolescent Statute (ECA), which maintains and deepens this social wound.

Keywords child labor; social being; subject of right; accumulation by dispossession; labor and human development. 


\section{Introdução}

Este artigo retoma concepções e práticas acerca do trabalho infanto-juvenil, analisadas na tese Trabalho infanto-juvenil: concepções, contradições e práticas politicas (Fonseca, 2006), e em elementos de duas investigações e duas ações de extensão em andamento, para problematizar, na relação trabalho e educação, as possibilidades deste ser social criança e adolescente. Dando continuidade aos estudos que fazemos desde 1993 sobre o trabalho precoce de crianças e (trabalho) desprotegido de adolescentes, atualmente investigamos uma política de erradicação do trabalho infanto-juvenil e uma Rede de Proteção (associada a um Conselho Tutelar), ambas políticas inseridas no escopo da proteção integral em acordo com o Estatuto da Criança e do Adolescente (ECA). Analisamos a relação entre trabalho e formação do infantojuvenil e de trabalhadores da educação e da assistência social, políticas que integram as condicionalidades para a bolsa do Programa de Erradicação do Trabalho Infantil (Peti) e que são fortemente comprometidas, através da Rede, com a proteção integral ao sujeito de direitos.

Trazemos, na historicidade da produção acadêmica sobre o tema, o diálogo com Grupo de Trabalho (GT) 9, Trabalho e Educação, da Associação Nacional de Pós-Graduação e Pesquisa em Educação (Anped), por três argumentos: ênfase do estudo na relação trabalho e formação (de crianças e adolescentes e dos trabalhadores de políticas que operam sobre o infanto-juvenil); imperativo de problematizar o trabalho da educação social/comunitária, tendo em vista a necessária intersetorialidade entre as políticas de educação e assistência social quer como 'escola de tempo integral' ou 'educação integral'; e a pouca de reflexão do GT sobre o tema. Vertentes da relação trabalho e educação na contemporaneidade da formação humana que não podem prescindir do materialismo histórico como campo teórico-metodológico de análise.

O artigo organiza-se em três seções: a historicidade do fenômeno social trabalho infanto-juvenil no processo de acumulação do capital, a produção acadêmica do GT Trabalho e Educação sobre o tema e a atualidade da questão. A exposição vinca o objeto trabalho infanto-juvenil como produto e motor da acumulação de capital, com nuances, permanecendo funcional ao acirramento da exploração porque, quando falamos na exploração da força de trabalho infanto-juvenil, além da expropriação pertinente à lógica do capitalismo, temos aproximações com um aprofundamento da extração de mais-valia absoluta, ou seja, obtida pela intensificação do uso da força de trabalho. No caso, roubando o tempo do infanto-juvenil que, pelo direito inscrito na legislação do estado burguês, deve brincar, adolescer, ir à escola, desenvolver múltiplas possibilidades na formação humana de forma integral - ser/viver infanto-juvenil. No entanto, as sucessivas reestruturações produtivas e os consequentes modos de gestão do Estado enfraquecem os 
movimentos na legislação trabalhista em nível internacional e, no caso brasileiro, os avanços representados pelo ECA, e, desta forma, banalizam a materialidade do sujeito de direitos.

\section{Trabalho infanto-juvenil e processo de acumulação do capital}

O trabalho infanto-juvenil compõe e reproduz a acumulação capitalista, constituindo, portanto, a composição orgânica do capital desde a acumulação primitiva (Marx, 1991) e, incidindo sobre o desenvolvimento desigual e combinado do capitalismo, mantém-se na contemporaneidade de acumulação por 'despossessão' (Harvey, 2004). As reestruturações produtivas ao longo da história vêm ratificando a afirmativa de Marx (1991) quanto ao caráter definitivo do uso da força de trabalho infantil na produção capitalista.

Os movimentos sociais inscreveram a particularidade do infanto-juvenil desde as lutas da classe operária inglesa pela regulamentação da jornada de trabalho (Marx, 1991; Thompson, 1987), passando pelas convenções da Organização Internacional do Trabalho (OIT). No Brasil, o marco conceitual e jurídico 'sujeito de direitos' sintetiza essa trajetória. Na concretude da vida, entretanto, a impunidade ou a precária consistência das estratégias punitivas constituem mostra inconteste da força do capital sobre o marco regulatório. Situação que acompanha e agrava as condições de trabalho de jovens e adultos constituindo-se, por sua precariedade, em possível forma de reserva de força de trabalho.

Quando expõe o início da acumulação capitalista, Marx (1991) cita o divórcio entre o trabalhador e a propriedade das suas condições de trabalho, um processo que a um só tempo transforma os meios sociais de vida e de produção em capital, e os produtores imediatos, em operários assalariados. A chamada acumulação primitiva constitui-se, portanto, no processo histórico de apartação do produtor e dos meios de produção; nomeada originária porque consiste na pré-história do capital e do modo capitalista de (re)produzir a existência social. Um tempo em que Marx, no Prefácio de 1859, quando se refere à produção social da vida e à determinação da consciência, nos instiga a pensar em camponeses - crianças, jovens e adultos - como trabalhadores assalariados no campo e na cidade, que passam a ter o sentido da existência mediada pela exploração do capital sobre a força de trabalho. E, portanto, a consciência social capturada pela perda da propriedade da sua força de trabalho e é nesta cultura que produzem sua existência material e moral.

Marx (1991) e Thompson (1987), tendo como base os Relatórios das comissões de emprego das crianças (1842), evidenciam o trabalho infantil pesado e em ofícios indignos, expandindo-se nas décadas iniciais do século XIX, em especial na industrialização nascente na Inglaterra, em zonas rurais 
trançando palha e renda. Marx denuncia as manufaturas, onde os patrões roubavam e escravizavam crianças de sete a 14 anos para moverem a roda hidráulica nas fábricas recém-construídas à beira dos rios por seus dedos finos e ágeis, fábricas cuja prosperidade atrelava-se às crianças pobres que, se revezando em turnos, perdiam o direito ao sono da noite. Os patrões vestiam, davam de comer, abrigavam-nas em casas de aprendizes no entorno da fábrica, sob o mando de capatazes, as crianças eram açoitadas, acorrentadas, torturadas, e morriam de fome ou trabalhando porque o intermediário recebia proporcionalmente à quantidade de trabalho arrancada das crianças. Ou seja, um infante, por ter sua vida precária, era submetido à exploração no trabalho desde tenra idade, miserabilizando ainda mais sua vida.

A formação estabelecia-se fora da família, entre vizinhos, amigos, amos e criados, crianças e velhos, mulheres e homens. É desde esta concepção que Ariès (1978) fala de uma infância historicamente (des)coberta na medida em que os adultos - o Estado e a sociedade - se perguntam o que fazer com as crianças. Afirma, ainda, que a escola substituiu a aprendizagem como meio de educação a partir do fim do século XVII. Criaram-se refúgios para guardar crianças; surgiram organizações para cuidar de lactentes. No final do século XVII apareceram as primeiras creches urbanas na França e Inglaterra; sob a ótica assistencialista, visavam afastar as crianças pobres do trabalho servil que o sistema capitalista em expansão impunha, além de servir como guardiãs de crianças órfãs e filhas de trabalhadores. Vem desde aí, para o centro de debate político, a guarda e a educação das crianças na legislação social e nas reformas escolares desde o século XVIII. As crianças da classe trabalhadora iniciam sua perambulação entre a necessidade material do trabalho precoce e a luta pelo direito a uma vida infantil que desfrute da escolaridade.

\section{Nas lutas por regulamentação da jornada de trabalho, regula-se a proibição do trabalho infantil}

A Revolução Industrial, na Inglaterra da metade final do século XVIII, conclui em um país de centro a transição entre feudalismo e capitalismo, e a acumulação de capital adquire a forma de capital mercantil. A escravidão dos tempos de transição entre o feudalismo e o desenvolvimento industrial se converteu em exploração capitalista com o assalariamento de crianças e jovens, feitos força de trabalho - mercadoria que produz mercadoria sem controle/conhecimento do produto de seu trabalho, de forma alienada, portanto. $\mathrm{O}$ advento da maquinaria estabelece um novo patamar no processo produtivo e nas relações de produção: de um lado, o capital detentor dos meios de produção e, de outro, o trabalho cuja força inscreve a pertença à esfera produtiva. A força de trabalho passa a constituir a única mercadoria 
capaz de criar valor, há um trabalhador livre que dispõe de sua força de trabalho e, sem dispor dos meios de produção, precisa vendê-la para produzir e reproduzir a vida. Mercadoria de valor igual ao de todos os produtos necessários à sua conservação e reprodução, considerando as necessidades básicas de sua família.

A superpopulação relativa em suas formas históricas constitui fonte inesgotável de força de trabalho para o capital e possibilita cooptação para qualquer emprego, com grandes jornadas e baixíssimos salários, tornando os trabalhadores dóceis à exploração do capital além de fiéis na balança para exploração e opressão capitalista sobre os trabalhadores empregados. O infanto-juvenil cuja extração de classe vive da venda de sua força de trabalho vem sendo produzido nesta perspectiva.

A luta de classes faz avançar a organização dos trabalhadores conquistando o direito à sindicalização, redução da jornada de trabalho, escopo em que se institui a condenação do trabalho noturno e outras formas prejudiciais de trabalho para crianças e mulheres. $\mathrm{O}$ acirramento das contradições no modo de produção e a luta de classes produziram avanços científicos, técnicos e tecnológicos na produção, novas formas de organização do trabalho e regulação das relações trabalhistas, tirando crianças e jovens da fábrica e lançando, outra vez, crianças e jovens nas ruas; porque perderam o lugar na fábrica sem encontrar possibilidades na escola.

Historicamente, a acumulação se mantém e se amplia por dois grandes movimentos: de um lado, a compressão espaço-tempo no processo de trabalho; de outro, a ampliação dos territórios, pela colonização. Assim, agravando a exploração em cada país e invadindo novos territórios para expropriar e espoliar, acentua-se o desenvolvimento desigual e combinado do modo capitalista de produzir e reproduzir a existência. Estruturalmente, a produção ajusta sua capacidade de aumentar os níveis de exploração e a superestrutura também se adapta. O Estado liberal organizou formas que protegiam e promoviam a continuidade e o aperfeiçoamento capitalista do modo de produção. É nesse escopo que o capitalismo europeu e americano alicerça leis de proteção aos trabalhadores para garantir o avanço da lógica de mercado.

O trabalho de crianças e jovens ocorria em parte dos ramos de atividades, e lutas específicas regularam a proibição do trabalho infantil pela OIT até 1973, quando a Convenção n. ${ }^{\circ}$ 138, vigorando a partir de 1976, propõe uma política nacional com vistas a abolição do trabalho infantil e a elevar progressivamente a idade mínima de admissão ao emprego ou ao trabalho. No entanto, eliminar toda e qualquer forma de exploração do trabalho infantil expressa na convenção, bem como os aperfeiçoamentos contratuais subsequentes, referentes à proibição ao trabalho forçado (escravo) e proibição à discriminação no local de trabalho continuam em disputa, e os 
países de capitalismo central são os que oferecem mais resistência a concretizar o objeto da Convenção.

Na "Crítica ao Programa de Gotha", Marx [1875] afirma que a proibição do trabalho infantil, se factível, seria reacionária. Defende severa regulamentação da jornada de trabalho, respeito às idades e medidas de proteção para as crianças. E, assim, combinar trabalho produtivo e aprendizagem desde a tenra idade potencializa transformações na sociedade. Do campo das concepções e práticas socialistas, ficam os grandes eixos fundantes do marxismo na educação: tomar o método dialético para compreender e intervir na realidade; (re)apropriar como classe trabalhadora acúmulo técnico, científico e cultural apropriado pela burguesia; entranhar a escola de política e vida; investir na auto-organização dos estudantes como forma de fomentar a democracia escolar; articular, no encontro entre instrução e trabalho produtivo, uma formação humana que desenvolva como totalidade o ser social; e potencializar a educação obrigatória, gratuita e universal em todos os níveis.

Do ponto de vista do capital, os estudos de Frigotto (1989) sobre a educação nas décadas de 1970 e 1980 apresentam os princípios da ideologia do capital humano. Associando economia e educação, educação/escola e trabalho/emprego, educação e crescimento e desenvolvimento econômico, a teoria do capital humano assentada na economia neoclássica e no positivismo/tecnicismo constitui-se em formulação sobre desenvolvimento e educação, antagônicos aos interesses da classe trabalhadora. Porque, como capital humano, a educação potencializa para o emprego, perdendo sua especificidade como formação humana; funcional ao capital e perversa ao trabalho, o fracasso na obtenção de emprego e renda são imputados à (in)apropriação da escola.

\section{$\mathrm{Na}$ acumulação flexível, lutas por democracia forjam cidadania e sujeito de direitos no Brasil}

A crise do capital impõe nova (re)estruturação produtiva, a produção toyotista de formato flexível, em contraposição à rigidez do fordismo-taylorismo; financeirização internacional e reajustamento político, social e cultural acompanham a emergência da nova racionalidade tecnológica que, associada à ideologia neoliberal, compõe os alicerces estruturais do novo padrão de acumulação. A expressão flexível envolveu processos de trabalho, mercados, produtos e padrões de consumo; fortaleceu desigualdades existentes no padrão de desenvolvimento entre setores e entre regiões, potencializou o setor de serviços. Flexíveis também se tornam as relações de trabalho, em detrimento da regulação existente. 
Flexibilidade/desregulamentação nas relações de trabalho e emergência do desemprego estrutural que agravam a miséria das famílias e intensificam a exploração do trabalho infanto-juvenil. Exploração que se aproxima da extração de mais-valia absoluta porque crianças e adolescentes têm uma jornada de trabalho indefinida, servindo como elemento de pressão sobre o emprego e a jornada de trabalho do trabalhador adulto. Também pela intensificação da produtividade porque com baixa ou nenhuma qualificação, para funções iguais as de um trabalhador adulto, crianças e adolescentes têm suas capacidades físicas violadas. E espoliação da vida infanto-juvenil privada do lúdico e da fruição essenciais à infância e à adolescência cultural, emocional, física e cognitivamente saudável. Além disso, vulnerabiliza-se a escolaridade e a formação humana, potencializando no âmbito da reprodução ampliada do capital a produção de um contingente de jovens e adultos sobrantes, 2 modo de reserva de força de trabalho na contemporaneidade. O Estado assume a ideologia neoliberal como doutrina, justificando terceirizações e privatizações, repassando para o setor privado paulatinamente funções até então públicas.

Na formação social brasileira, a década de 1980 foi extremamente forte, os movimentos sociais fortalecidos pela superação da ditadura civil-militar intensificaram a luta política por cidadania e apontaram para a construção de um sujeito de direitos. Necessário perceber que a realidade das crianças e adolescentes na rua desnudava a vida de milhões de famílias nas periferias urbanas que sobreviviam em condições indignas, cuja base estava no chamado êxodo das zonas rurais pauperizadas, que expulsaram milhões de famílias do campo em direção às periferias das regiões metropolitanas nas médias e grandes cidades deste país. A expulsão da população rural do meio em que vivia constituiu-se em mostra da falência do propalado modelo agrário-exportador como propulsor do desenvolvimento no país e, também, indicou o processo de industrialização fordista em curso. Importa frisar que a luta travada no sentido de ampliação dos direitos da cidadania não repercutiu com a mesma intensidade no campo econômico.

O marco jurídico-político desta luta, inscrito no caput do artigo 227 da Constituição de 1988, fundamentado na Convenção Internacional dos Direitos da Criança (1989), garante os direitos sociais à educação, à saúde, ao trabalho, ao lazer, à segurança, à previdência social, à proteção à maternidade, à infância e à assistência aos desamparados, e proíbe o trabalho noturno, perigoso ou insalubre aos menores de 18 anos e qualquer trabalho aos menores de 14 anos, salvo na condição de aprendiz, proteção também prevista no ECA. Regime de aprendizagem cuja regulamentação, remetida à lei n. ${ }^{0}$ 9.394/1996 (Lei de Diretrizes e Bases da Educação Nacional - LDB), vem legitimando mais a forma trabalho do que aprendizagem. O ECA estabelece o trabalho educativo como forma de educação e geração de renda, 
priorizando os aspectos educativos sobre os produtivos, importa precisar o sentido do educativo.

A Convenção n. ${ }^{\circ} 182$ (OIT, 1999) trata Sobre Proibição das Piores Formas de Trabalho Infantil e Ação Imediata para sua Eliminação, entrando em vigor em 2000. O texto considera necessário adotar novos instrumentos para coibir e eliminar as piores formas de trabalho infantil, como a principal prioridade de ação nacional e internacional. Retoma a vinculação entre trabalho infantil e escolaridade, requerendo ação imediata e global que leve em conta a importância da educação fundamental e gratuita e a necessidade de retirar a criança das formas de trabalhos nomeadas 'piores', promover sua reabilitação e integração social e, ao mesmo tempo, atender às necessidades de suas famílias. Alia universalização da educação e alívio à pobreza para justificar a necessidade de eliminar o trabalho infantil.

Em 2000, o Brasil ratifica a convenção acima citada e, apenas em 2001, ratifica a Convenção $n .^{\circ} 138$ (1973) sobre a idade mínima para o emprego: 16 anos. Posterior ao ECA, a lei n. ${ }^{\circ} 10.097 / 2000$ altera os artigos da Consolidação das Leis Trabalhistas (CLT) que tratam da proteção do trabalho, a partir de 2000 "considera-se menor (grifos nossos) para os efeitos desta Consolidação o trabalhador de 14 até 18 anos". Fica proibido "qualquer trabalho a menores de 16 anos de idade, salvo na condição de aprendiz, a partir dos 14 anos". O grifo chama atenção de que, embora o ECA já tivesse dez anos, o discurso jurídico continuava ignorando 'o sujeito de direitos', discriminando e criminalizando a priori os filhos e as filhas das classes trabalhadoras, famílias submetidas a formas precárias de trabalho ou em situação de desemprego.

\section{O trabalho infanto-juvenil e o GT Trabalho e Educação}

Utilizando o CD-ROM dos 25 anos da Anped, forma de acesso aos trabalhos da década de 1990, e os trabalhos expostos no sítio do GT Trabalho e Educação após esta data, dialogamos com a presença do tema nesse grupo de trabalho analisando pôsteres, comunicações e trabalhos aprovados (apresentados ou não), que referiam o trabalho infanto-juvenil para apreender o lugar do tema no campo. Foram 16 reuniões anuais - da $16^{a}$ à $31^{a}-$, das sete produções (trabalhos ou comunicações), cinco estão disponibilizadas. As comunicações da $16^{\mathrm{a}}$ e da $17^{\mathrm{a}}$ Reunião Anual, intituladas Trabalhar e estudar não é brincadeira: um estudo sobre o lúdico e o lazer de crianças trabalhadoras (Carrano, 1993) e Em busca de jovens vozes (Anjos, 1994), não estão acessíveis e por isso não foram analisadas.

O trabalho Alunos do noturno: quem são estes trabalhadores, de Arrais (1995), apresentado na $18^{\text {a }}$ Reunião Anual, tendo por sujeitos da pesquisa adolescentes cursando o ensino supletivo, tratou de verificar 
(...) até que ponto o trabalho educativo desenvolvido em uma experiência singular leva à consciência-em-si ou à consciência-para-si, em termos do nível de superação da ideologia dominante e constituição de uma nova práxis por parte dos alunos (Arrais, 1995, p. 1).

Sustentada na perspectiva gramsciana de que o trabalho industrial (capitalista) demonstra ser efetivamente um grande educador, uma vez que formata a cultura urbana, hábitos, valores e costumes, embora considere o amplo de mundo do trabalho como mundo social e cultural onde estamos inseridos desde a mais tenra idade, Arrais pondera a especificidade da entrada no mercado de trabalho porque se dá com incorporação do regramento ditado pela lógica do capital. Assim, a autora analisa dois aspectos da inserção: de um lado, desumanizante e reificadora do trabalhador; e de outro, formadora do 'trabalhador coletivo', ser habituado à cultura do trabalho, às lutas decorrentes, e "ao consequente processo (dialético) de constituição de uma consciência classista, reflete-se com bastante impacto sobre a realidade escolar diferenciada do aluno do noturno" (Arrais, 1995, p. 4). Dos dois grupos entrevistados, um começou a trabalhar antes dos dez anos, no campo; o outro, depois dos dez anos, na cidade. É nesse segundo grupo que Arrais observa, pelo relato dos pesquisados,

o caráter formador para o trabalho da educação doméstica e da divisão familiar de trabalho numa perspectiva consideravelmente adaptada às necessidades sociais da formação dessa mão de obra específica que são os empregados domésticos (Arrais, 1995, p. 5).

Questiona se há uma precoce idade adulta ou uma adolescência tardia, tomando características biopsicoafetivas da adolescência que

incluem solidão, inconstância, insegurança, descoberta das relações sexuais e afetivas e reflexão sobre suas histórias de vida e o sentido mais global de suas existências, bem como os primeiros indícios da crítica dos modelos sociais e econômicos, embora feitas ainda a partir de uma visão ingênua do senso comum (Arrais, 1995, p. 7),

para afirmar que se constitui numa árdua prova de personalidade para os estudantes a vivência de um tempo que se faz amalgamando adolescência e juventude, momentos por si tão delicados na constituição das individualidades. Para a pesquisadora, esse sentido produz, dialeticamente, a educação para a exclusão, ou, no marco teórico gramsciano, uma pedagogia para a subalternidade, a formação do ser social que se reconhece como não-principal, pertencente a uma classe subalterna, "de inculcação da opressão, 
através do 'consentimento' da dominação" (Arrais, 1995, p. 7). Reportando a Althusser, demarca o papel da capacitação técnica e da submissão política como elementos fundamentais da reprodução ideológica perpetrada pelos Aparelhos Ideológicos de Estado (AIE). Concluindo, sinaliza que

se na primeira infância acontece o aprendizado da pobreza e da dureza da vida no trabalho braçal, agora se sobrepõe a vivência de suas experiências de 'ser pessoa' subalterna, tanto sob os aspectos emocional, afetivo, sexual, quanto social, e a partir daí abre-se as portas para a subcidadania (Arrais, 1995, p. 7 ).

A comunicação de Leite (1995), Criança-trabalhadora: a práxis na rua, parte de pesquisa com crianças-trabalhadoras na rua, menores de 14 anos, alijadas do saber escolar, mas educadas nas relações de trabalho. Sua questão perpassa o princípio educativo que conduz à formação e sua configuração no momento histórico. Inserindo o trabalho infantil no sistema capitalista de produção e os saberes decorrentes, a autora propõe uma organização escolar articulando cientificamente os conhecimentos adquiridos na práxis do trabalho e a dinamicidade das relações sociais. Do aporte gramsciano de que o trabalho é princípio educativo por seu conteúdo e forma, e da definição de infância da OIT como tempo de vida, em que estudo, lazer, felicidade, (des)compromisso, imaturidade, contraditam com a realidade vivenciada pela criança pobre a quem são negadas essas referências, retoma indicações da OIT, que apontam no Brasil uma naturalização do trabalho infantil como solução para as necessidades da criança pobre e miserável. Alerta a pesquisadora que o reconhecimento dos saberes que a criança desenvolve em sua práxis na rua impõe compreender algumas

peculiaridades do funcionamento do sistema que tem, na criança, uma mão de obra especial: ágil, barata, abundante, fácil de manipular em função da idade, da ilegalidade do trabalho e da índole não especializada do mesmo. Ainda nessa problemática, o trabalho se efetiva na infância do segmento social marginalizado até mesmo dentro do proletariado (Leite, 1995, p. 3).

Um debate negligenciado nas negociações sindicais que, apesar de não ser moralmente aceito, sua manutenção é indício revelador da funcionalidade na subocupação no sistema produtivo em sua totalidade, o que ratifica a necessidade de estudá-lo no âmbito da totalidade social do trabalho humano no capitalismo, ainda mais que os estudos do Instituto Brasileiro de Geografia e Estatística (IBGE) indicam a amplitude numérica e seu revigoramento na realidade brasileira. Os resultados da investigação revelam que a aparência de exclusão do sistema produtivo induzida pela subocupação produz a essência da exclusão: "pelo tipo e longa jornada de trabalho (regime 
extensivo), as crianças ficam à margem do direito à proteção integral, princípio aceito na Convenção Internacional de Direitos da Criança e referendado pelo ECA" (Leite, 1995, p. 4); o trabalho da criança na subocupação constitui ligação mediadora entre o trabalho formal e o informal, no mercado local, nacional e internacional, com maior intensidade de exploração; o volume de trabalho produzido pelas crianças é de grandes proporções (caso dos catadores de papel); enquadrado em geral como prestação de serviços urbanos, há materialidade do trabalho infantil na produção agrícola, industrial e de serviços; além das estratégias de sobrevivência do segmento social de pertença, a criança trabalhadora realiza aprendizagens singulares a cada ocupação e instituição da qual faz parte; e a criança desenvolve mecanismos de resistência e habilidades que são apontadas pelo mercado como atitudes fundamentais ao empresário do terceiro milênio. A criança trabalhadora pleiteia como utopia o direito à infância com estudo e lazer, enquanto em sua prática laboral usa a cidade como espaço de produção e aprendizagem.

Na 19a Reunião Anual, o trabalho Trabalhadores infanto-juvenis de escolas de primeiro grau contribui para repensar o currículo de Osowski e Gue Martini (1996). A pesquisa relaciona as representações sociais de trabalho e currículo escolar, pontuando a diversidade de disciplinas onde a produção social da existência se faz presente. Tratando o termo representações sociais "tanto como o conjunto de fenômenos quanto o conceito que os engloba e a teoria construída para explicá-los, identificando um vasto campo de estudos psicossociológicos" (Osowski e Gue Martini, 1996. p. 1) e compreendendo que se produzem "com base nas relações de produção da vida e dos bens necessários à sua reprodução"(Osowski e Gue Martini, 1996. p. 1). Aliam essa concepção de trabalho como produção de vida à representação do trabalho "como ascensão social, associado a quesitos morais como honestidade, responsabilidade, pontualidade e esforço pessoal, reproduzindo a compreensão do processo produtivo hegemônico nas sociedades capitalistas" (Osowski e Gue Martini, 1996. p. 1). Lembram que, historicamente, a criança e o jovem são preparados para participar das relações sociais de produção e, desde os séculos XII e XV, as tarefas domésticas confundem-se com a aprendizagem, como uma forma geral de educação. Assim, fundado na necessidade de acumulação no modo de produção, na valorização familiar, comunitária e grupal, e assentado na história, o trabalho infanto-juvenil vai sendo legitimado ideologicamente e, no contexto escolar, inscrito num currículo oculto que (in)visibiliza a realidade deste sujeito social em particular. Um modo de trabalho que se sedimenta culturalmente no silêncio e impõe solução de continuidade entre a produção da vida e a produção na escola. As autoras chamam atenção ainda para uma peculiaridade do trabalho doméstico quando realizado num ambiente 'quase familiar' porque favorece a negação de direitos trabalhistas e o silencia sobre os direitos da criança; pior, 
por um assujeitamento baseado em trocas afetivas, crianças, adolescentes e seus familiares, gratos pelo acolhimento, trocam serviços. Salientam as pesquisadoras que "o trabalho doméstico foi configurando-se e configura-se ainda hoje como um referencial para aprendizagens de uma maneira de ser na sociedade e, em especial, no próprio mundo do trabalho" (Osowski e Gue Martini, 1996. p. 7), uma vez que raramente aparece como trabalho propriamente dito. E, por fim, seus estudos nos instigam a compor rupturas e coibir abusos para instituir o inscrito na Constituição brasileira e na legislação ordinária sobre a criança e o adolescente. E explicitam a perspectiva de que a pesquisa contribua para questionar e discutir aspectos pertinentes ao trabalho infanto-juvenil,

buscando assegurar territórios fortes para que as crianças e adolescentes menores de 14 anos possam construir subjetividades que os levem a se tornar cidadãos e cidadãs comprometidos política e socialmente com a construção de uma sociedade mais justa e digna" (Osowski e Gue Martini, 1996, p. 9).

A $24^{a}$ Reunião Anual, em 2001, trouxe o pôster Programas de inserção socioprofissional de jovens na região metropolitana de Belo Horizonte, Minas Gerais, de Leão (2001), que, apesar de não tratar especificamente do trabalho infanto-juvenil, tem aproximações com o objeto porque articula juventude e mundo do trabalho. Aborda o desenvolvimento de experiências de programas públicos de inserção socioprofissional com jovens da região metropolitana de Belo Horizonte, com vistas a compreender o papel atribuído à formação geral e profissional como instrumento de integração social e de inserção no mercado de trabalho dos jovens atendidos e esclarecer a relação desses programas com as questões postas pela reestruturação capitalista como o desemprego e o subemprego juvenil, as situações de marginalidade e de expansão da violência entre os jovens etc. Questiona: esses programas, como políticas públicas de trabalho, estão se pautando por uma visão mais ampliada da relação trabalho e educação?; que padrão de inserção no trabalho tais iniciativas privilegiam?; não estaria se repetindo a velha matriz de uma formação empobrecida para os pobres, voltada para o adestramento e a moralização?; e qual a relação entre as atuais mudanças no mercado de trabalho - em que as ocupações tornaram-se precárias e transitórias - e os programas pesquisados?

Na 25a Reunião Anual, em 2002, o trabalho Jovens olhares sobre o trabalho, de Corrochano, se refere ao labor entre jovens operários e operárias entre 18 e 24 anos em três indústrias do setor de autopeças da cidade de São Bernardo do Campo. A autora informa que a idade média de entrada no mercado de trabalho do grupo investigado girou em torno de 14-15 anos, mas grande parte começou a trabalhar antes da idade permitida por lei 
(Corrochano, 2002, p. 5), o que para mim não fica claro, uma vez que na faixa etária explicitada no trabalho, exceto na condição de aprendiz, é ilegal. Ratificando a precariedade de vida e trabalho do grupo analisado, afirma que a indústria foi a porta de entrada para percentual significativo e que as ocupações mais frequentes eram as de auxiliar de montagem, ajudante de produção, embalador e office-boy - tarefas pouco qualificadas e que a maioria continua realizando atualmente (Corrochano, 2002, p. 5).

A revisão dos trabalhos no GT Trabalho e Educação evidencia a ausência da temática entre 2002 e 2008.

\section{Tempos de 'despossessão' e banalização do sujeito de direitos}

Vimos o tempo infanto-juvenil no corte de classe social marcado por recorrentes precariedades e discriminações: abandonado, menor, pivete, marginal, delinquente, menino na rua, menina de rua, criança inserida precocemente na exploração do trabalho, adolescente desprotegido no mundo do trabalho, crianças e adolescentes explorados comercial e sexualmente. Explorados pelo capital e, cada vez mais, objeto de políticas de governo em vez de sujeitos nas políticas de Estado. O ECA avançou ao propor a categoria 'sujeito de direitos', associando-a à doutrina da proteção integral. Isso representa uma vitória da luta política. No entanto, mesmo em governos que se afirmam no campo democrático e popular, há limites nas ações desenvolvidas porque as políticas públicas que atendem a classe trabalhadora estão desarticuladas e esgarçadas, e o Estado vem sendo paulatinamente enxugado para o campo do trabalho potencializando ações focais e enfraquecendo políticas permanentes e universalizantes. Disso decorre, entre outras questões: continuidade e aprofundamento da expulsão na/da escola; distorções na concepção de trabalho (como princípio) educativo, nas políticas de combate ao trabalho infanto-juvenil; e trabalhadores da escola e da educação social com precária formação básica e continuada em serviço. Um conjunto de insuficiências que aprofundam a pobreza e alimentam desigualdades no campo dos direitos e, portanto, erradicam possibilidades de dignidade de vida para a prole da classe trabalhadora.

Conceituamos trabalho infanto-juvenil como toda prática laboral - formal ou informal - realizada por crianças e adolescentes, menores de 18 anos, sem caráter educativo, desrespeitando os limites do sujeito, com riscos diretos ou indiretos, como estratégia de sobrevivência, remunerada direta ou indiretamente, desenvolvida em casa ou na rua, caracterizando exploração da força de trabalho. E, mesmo quando travestido de ajuda, a forma de trabalho explicita marcas de classe, etnia e gênero. Compreendendo que a contradição principal do fenômeno crianças e adolescentes inseridos de forma 
precoce e/ou desprotegida no mundo do trabalho está no enfraquecimento da potencialidade ontológica dessa forma de trabalho, isto é, quando fazemos o corte geracional, o trabalho, categoria fundante do ser social e cuja centralidade determina a vida humana, torna-se mutilador do presente e do futuro; não raro, reproduzindo vivências familiares. Essa componente estrutural agrava-se na medida em que o capital prescinde de sua capacidade civilizatória e acirra a acumulação, avançando sobre os direitos dos trabalhadores, incluindo os fundos constituídos para amenizar as desigualdades sociais; ou seja, acumula desapossando conquistas e recursos (Harvey, 2004).

Em nível mundial, essa força de trabalho garante redução de preço nas mercadorias exportadas. Tal como outras formas precárias de relações trabalhistas, assegura, na esfera internacional, desigualdade no desenvolvimento combinado do capitalismo. Em países como o Brasil, garante dependência do padrão de acumulação, essa força de trabalho assegura produção imediata a baixo custo e, de forma mediata, produz 'sobrantes' (Marx, 1991). Como classe, os trabalhadores têm seu cotidiano imbricado pela dualidade trabalho manual/trabalho intelectual, coexistência essa que, historicamente, estende-se ao campo educacional como disputa entre uma formação geral e a especificidade na organização do currículo, demarcando hierarquia de classe (Kuenzer, 1991). Exemplificando pela relação educação escolar e formação profissional, a autora expõe rupturas entre processos formativos com vista à cidadania ativa e formas de adestramento para qualquer emprego. No corte geracional, acirra processos de exclusão na/da escola, situação agravada uma vez que nessa frágil política de Estado proliferam políticas de governo onde tanto o Estado quanto parte da sociedade civil servem ao capital por meio de projetos e programas com vistas a, no limite, aliviar à pobreza.

A última PNAD, de 2006, contou 1,4 milhão de crianças e adolescentes entre cinco e 14 anos trabalhando. Nessa faixa, 49,4\% estão no mercado de trabalho e cumprem jornada doméstica, principalmente as meninas. Dos 15 aos 17 anos, 24,8\% abandonaram a escola pelo trabalho doméstico, ou para procurar trabalho. Apesar desse quadro de trabalho infantil e inserção no trabalho doméstico, 75,8\% das crianças e adolescentes de 0 a 17 anos frequentavam a creche ou escola em 2006. No entanto, os indicadores não indagam a qualidade dessa frequência, ou seja, se ela assegura permanência e conclusão. Aproximadamente 80,0\% dessas moram em domicílios cujo rendimento médio mensal domiciliar per capta era menor que um salário mínimo. Como em estudos clássicos sobre a temática, o recenseamento associa trabalho infanto-juvenil, baixa escolaridade e baixa renda das famílias em que vivem.

Uma panorâmica da comunidade com a qual trabalhamos revela crianças e adolescentes capturadas para atuar como 'avião' ou olheiro no tráfico 
de drogas, submetidas à exploração sexual e comercial, trabalhando na catação de lixo seco, inseridas no trabalho domiciliar e doméstico - formas ilegais, insalubres, penosas, perigosas e/ou invisíveis. Seus familiares são trabalhadores domésticos, nem sempre com carteira assinada, terceirizados, cooperativados, prestadores de serviço, trabalhadores ou proprietários de pequeno comércio local, catadores, traficantes... Uma realidade violadora de direitos da família e da comunidade, haja vista o papel desempenhado pelo Estado quando impõe limites às condições materiais para o artigo 15 do ECA: "A criança e o adolescente têm direito à liberdade, ao respeito e à dignidade como pessoas humanas em processo de desenvolvimento e como sujeitos de direitos civis, humanos e sociais garantidos na Constituição e nas leis."

Dados agravados quando a empiria na escola básica e na educação social demonstra que as políticas de atenção à infância e à adolescência estão, de fato, centradas na precarização seja como política de Estado, seja como políticas de governo. Como política de Estado, a Educação, por exemplo, os trabalhadores, mesmo os concursados, vivem situação de arrocho salarial, sobretrabalho, desrespeito às conquistas de planos e cargos e salários (quando foram materializadas) e frágil ou inexistente formação continuada e/ou em serviço. Cada vez mais os governos utilizam contratos precários/temporários em detrimento dos critérios das políticas de Estado: servidor concursado, com formação básica, continuada e em serviço, respeitando os planos de cargos e salários. Quando a política social é executada no formato de política de governo, caso da Assistência Social, em especial das ações socioeducativas (jornada ampliada e trabalho educativo) a situação é ainda mais grave, porque essas políticas são majoritariamente terceirizadas e parte da chamada sociedade civil que deveria fazer o controle social das políticas é cooptada pelo repasse de dinheiro público e a possibilidade de emprego, enfraquecendo sua potência reivindicativa.

Nosso trabalho atual ${ }^{3}$ demonstra que as crianças e os adolescentes inseridos no Peti podem cumprir as condicionalidades de $85 \%$ de frequência à escola e inserção na jornada ampliada; entretanto, não há garantia de apropriação dos conhecimentos escolares e, pela precariedade do socioeducativo, a inserção nestas atividades de contraturno não significa potência na educação social. Na verdade, trabalhamos com indícios de dupla violação de direitos e, no limite, uma aproximação com o que a saúde pública nomeia de 'redução de danos': ou seja, políticas e segmentos constituídos para o controle social de ações inscritas como violação de direitos, ao não superarem a mazela social a que se propõem, são, outra vez, violadores de direitos. Em perspectiva semelhante, constatamos que, apesar de estarem na escola e na jornada ampliada, aquelas crianças e adolescentes que recebem bolsa Peti continuam trabalhando, o que nos instiga a buscar aproximações com o sentido atribuído à 'redução de danos', como se o encurtamento da jornada de 
trabalho fosse a superação possível para um grupo social que não irá deixar de ser explorado de forma precoce e/ou desprotegida pelas diversas faces com que o capital se apresenta no mundo do trabalho.

Podemos depreender da revisão feita e da empiria, tanto tomada ao longo da tese que, por entrevistas e oficinas, analisou concepções e práticas sobre o trabalho infanto-juvenil em espaços de protetivos, como na atualidade das pesquisas e da extensão que a dupla face do trabalho (Frigotto, 2002) para este grupo socioetário encontra materialidade na exploração e na organização da vida para a precariedade. Assim, este ser social tem no trabalho e nas políticas protetivas formas de reificar a mutilação de sua vida, de organizála na e para a precariedade. Despossuído de possibilidades de autonomia como sujeito, modo inerente às concepções e práticas das políticas assistencialistas, potencializando a formação de um grande contingente de sobrantes, reféns de 'políticas menores' que banalizam o sujeito de direitos.

\section{Notas}

1 Professora Adjunta do Departamento de Estudos Especializados da Faculdade de Educação da Universidade Federal do Rio Grande do Sul (DEE/Faced/UFRGS) e coordenadora do Núcleo Interdisciplinar de Ensino, Pesquisa e Extensão em Educação de Jovens e Adultos (Niepe-EJA) da Faculdade de Educação da Universidade Federal do Rio Grande do Sul, Porto Alegre, Rio Grande do Sul, Brasil. Doutora em Educação pela Universidade Federal Fluminense (UFF). <l.sfonseca@uol.com.br>

Correspondência: Rua Ramiro Barcelos, 2.129, apto. 22, Rio Branco, Porto Alegre, Rio Grande do Sul, Brasil, CEP 90035-007.

2 Exército de reserva de trabalho, exército industrial de reserva, ou superpopulação relativa, para Marx (1991) a existência de uma reserva de força de trabalho desempregada e parcialmente empregada, potencialmente desempregada, é uma característica inerente à sociedade capitalista, criada e reproduzida diretamente pela própria acumulação de capital.

${ }^{3}$ No momento, realizamos duas ações extensionistas em escolas públicas e espaços socioeducativos, uma pesquisa sobre violação de direitos numa rede de proteção, atividades desenvolvidas na mesma comunidade urbana na periferia de Porto Alegre, no Rio Grande do Sul, e estamos compondo o estado da arte sobre o trabalho infanto-juvenil nas instituições de ensino superior da região metropolitana de Porto Alegre. 


\section{Referências}

ARIÈS, Philippe. História social da criança e da família. Rio de Janeiro: Guanabara Koogan, 1978.

ARRAIS, Cristiane Holanda. Alunos do noturno: quem são estes trabalhadores. Trabalho apresentado no GT Trabalho e Educação, 18 ${ }^{a}$ Reunião Anual. 1995. In: ANPED, 25 anos. CD-ROM.

CORROCHANO, Maria Clara. Jovens olhares sobre o trabalho. apresentado no GT Trabalho e Educação, 25ª Reunião Anual. 2002. In: ANPED, 25 anos. CD-ROM.

FONSECA, Laura Souza. Trabalho infantojuvenil: concepções, contradições e práticas políticas. 2006. Tese (Doutorado em Educação) - Universidade Federal Fluminense. PPG EDU, Niterói.

FRIGOTTO, Gaudêncio. A produtividade da escola improdutiva: um (re)exame das relações entre educação e estrutura econômicosocial capitalista. São Paulo: Cortez, 1989.

A dupla face do trabalho: criação e destruição da vida. In: FRIGOTTO, Gaudêncio; CIAVATTA, Maria (Org.). A experiência do trabalho e a educação básica. Rio de Janeiro: DP\&A, 2002.

HARVEY, David. Condição pós-moderna: uma pesquisa sobre as origens da mudança cultural. São Paulo: Loyola, 2003.

O novo imperialismo. São Paulo: Loyola, 2004.

KUENZER, Acácia. Educação e trabalho no Brasil: o estado da questão. Brasília: Inep; Santiago: Reduc, 1991.

LEITE, Marinê Fecci Batistão. Criança-trabalhadora: a práxis na rua. Trabalho apresentado no GT Trabalho e Educação, $18^{\mathrm{a}}$ Reunião Anual. 1995. In: ANPED, 25 anos. CD-ROM
LEÃO, Geraldo. Programas de inserção sócio-profissional de jovens na região metropolitana de Belo Horizonte, MG. Pôster apresentado no GT Trabalho e Educação, $24^{a}$ Reunião Anual. 2001. In: ANPED, 25 anos. CD-ROM.

LUKÁCS, Georg. As bases ontológicas do pensamento e da atividade do homem. Temas de ciências humanas, n. 4. São Paulo: Livraria Editora Ciências Humanas, 1978.

MARX, Karl. Manuscritos econômico-filosóficos. Textos filosóficos. Lisboa: Edições 70, 1975.

Para a crítica da economia política: o método da economia política. Os economistas. São Paulo: Abril Cultural, 1982.

El Capital I: Crítica de la Economía Política. México: Fondo de Cultura Económica Clásicos de Economía, 1991.

. Critica del Programa de Gotha. In: MARX, Karl; ENGELS, Friedrich. Obras Escogidas. Moscou: Editorial Progreso, [1875].

OSOWSKI, Cecília; MARTINI, Jussara G. Trabalhadores infanto-juvenis de escolas de primeiro grau contribuindo para repensar o currículo. Trabalho apresentado no GT Trabalho e Educação, 19ª Reunião Anual. 1996. In: ANPED, 25 anos. CD-ROM.

THOMPSON, E.P. A formação da classe operária inglesa. A maldição de Adão. v. 2. Rio de Janeiro: Paz e Terra, 1987.

Recebido em 25/06/2009

Aprovado em 20/03/2010 